\title{
Mitochondrial Proteomics: From Structure to Function
}

\author{
Bernardo A. Petriz, Jeeser A. Almeida, Mirna S. Freire, \\ Luiz A. O. Rocha, Taia M. B. Rezende and Octavio L. Franco \\ Center of Proteomic and Biochemical Analyses, Postgraduate \\ Program in Genomic Sciences and Biotechnology, \\ Catholic University of Brasilia, Brasilia-DF \\ Brazil
}

\section{Introduction}

Mitochondria may be considered an evolutionary product originating from the endosymbiotic process of an aerobic bacterium with a protoeukaryotic cell, which started about 2 billion years ago. This hypothesis was based on the similarities in DNA and protein synthesis machinery between prokaryotic and eukaryotic cells (Margulis, 1970). In 1890, Altmann, who termed this organelle the "bioblast", concluded that these were elementary organisms for performing vital functions (Ernster \& Schatz, 1981). Furthermore, in 1898 Benda introduced the name "mitochondrion" from the Greek (Mitos: thread and Chondrion: granule). Other authors showed the appearance of these structures during spermatogenesis (Ernster \& Schatz, 1981) and defined them as subcellular organelles commonly found in the cytoplasm, with essential functions of aerobic metabolism for eukaryotic cells. These organelles have a wide plasticity and mobility, allowing some modifications in shape. Mitochondrial movement into the cytosol has been associated with microtubules, which may determine organelle organization in different cell types (Yaffe, 1999). Mitochondria can form long filaments of mobile chains, as observed in cardiac muscle cells, or be fixed into a single position as studied in sperm flagella (Yaffe, 1999). The number of mitochondria per cell may also vary according to cell type, usually located in high ATP utilization regions such as cardiac muscle and liver (Frederick \& Shaw, 2007; Scheffler, 2008). This organelle also occupies a considerable portion of the cytoplasmic volume, being essential for the evolution of a number of organisms.

Mitochondria are also involved in several central metabolic pathways that are important for cell function, modulation of cytosolic $\mathrm{Ca}^{+2}$ signaling, determination of cell death (apoptosis) (Camara et al., 2011), aging and associated diseases (Kowald \& Kirkwood, 2011), autophagous embryonic development (Ong \& Hausenloy, 2010), as well as being a continuous source of superoxide and reactive oxygen species (Stowe \& Camara, 2009; Koopman et al., 2010). Nevertheless, the main function of mitochondria is to generate chemical energy sources (ATP) through oxidative phosphorylation (Saraste, 1999), acting as the organism's "powerhouse". Without the presence of this particular organelle, animal cells would depend on anaerobic glycolysis for their energy production, which would be 
completely insufficient to meet demand. Mitochondrial metabolism of sugars is considered highly efficient, producing more energy than the glycolysis pathway.

Each mitochondrion has its own DNA and RNA with a complete system of transcription and translation, which synthesizes only a few proteins (Yoon et al., 2010). The mitochondrial genome of different tissues differs in size and gene content (Gray et al., 1999). In mammals, the mitochondrial genome is composed of a circular DNA molecule that has been reduced to approximately $16.5 \mathrm{~kb}$ in size, encoding genes for only 13 proteins, all of them indispensable for electron transport chain functioning. The human mitochondrial genome is composed of a single double-stranded DNA molecule that curiously does not have an intron, but contains 37 genes essential to the mitochondrial respiratory function (Wallace, 1999). Moreover, two ribosomal RNAs and 22 transfer RNAs are absolutely crucial for the mitochondria translation system (Yoon et al., 2010). All other genes responsible for normal mitochondrial operations are encoded in the cell nucleus (Wallace, 1999).

Mitochondria have a double membrane system and are structurally divided into four compartments: inner membrane, outer membrane, matrix and intermembrane space (Chan, 2006), as represented in Figure 1. Several porin molecules are present in the outer mitochondrial membrane. Porins are transporter proteins, which form aqueous channels through the lipid bilayer (Schirmer, 1998). Thus, the outer membrane functions as a filter, being impermeable to molecules above 5,000 kDa (Weissig et al., 2004). However, larger proteins can enter the mitochondrion through an $\mathrm{N}$-terminus signal sequence connecting it to a specific protein (outer membrane translocase), located in the outer mitochondrial membrane (Herrmann \& Neupert, 2000). An outer membrane disruption can lead to a

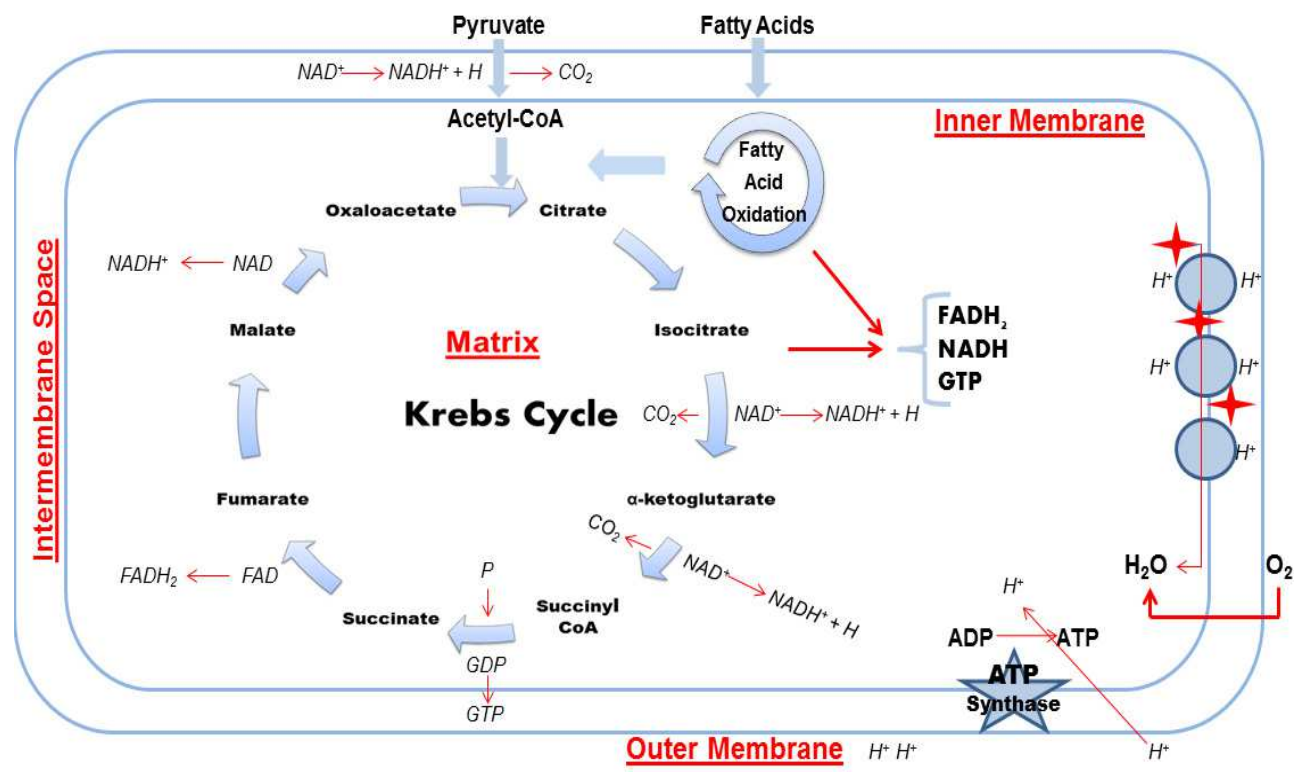

Fig. 1. Scheme of the structure and function of mitochondria by a diagrammatic representation of the Krebs cycle, electron transport chain and ATP synthesis. 
diffusion of proteins into the cytosol, inducing possible cell death (Chipuk et al., 2006). The intermembrane determines the space between the outer and inner membrane. Some proteins enter the intermembrane space, but they do not show the ability to penetrate the inner membrane due to enhanced hydrophobicity (Yoon et al., 2010).

The inner membrane is characterized by a major phospholipid structure termed cardiolipin. This structure consists of four fatty acids, allowing the membrane potentially to become impervious to almost all molecules (McMillin \& Dowhan, 2002). The membrane is convoluted in form, due to the presence of numerous cristae, which tend to be projected into the matrix, considerably increasing the inner membrane area. Interestingly, mitochondria from heart muscle cells have three times more cristae than those from liver cells (Alberts et al., 2002). Possibly this difference occurs due to ATP demand for different cell types. Inside the inner membrane there is a widely varying number of transporter proteins, which provide limited permeability and assist the entry and exit of ions and molecules that are required or metabolized by enzymes located in the mitochondrial matrix (Herrmann \& Neupert, 2000). In summary, the inner membrane proteins have basically three categories and corresponding functions: ATP synthase which produces ATP in the matrix, carrier proteins to regulate the passage of metabolites from within the matrix to outside it, and proteins involved in oxidation reactions in the respiratory chain.

The matrix is considered the highly functional zone inside mitochondria, due to its responsibility for ATP production (Krebs, 1940). It also contains mitochondrial DNA, RNA and ribosome special carriers. The matrix contains a vast amount of the enzyme responsible for the tricarboxylic acid cycle (TAC), also known as the Krebs cycle. This produces $\mathrm{NADH}+\mathrm{H}^{+}$and $\mathrm{FADH}_{2}$, essential for ATP synthesis by electrons donated to the electron transport chain (Krebs, 1940). These electron pairs are transferred to an $\mathrm{O}_{2}$ molecule to form $\mathrm{H}_{2} \mathrm{O}$ molecules. In this way, protons are loaded from the intermembrane space to the mitochondrial matrix by ATP synthase enzyme, yielding ATP for each proton loaded (Ernster \& Schatz, 1981).

\section{Classic and novel techniques applied to the mitochondrial proteome}

Progress in mitochondrial research has been made with a range of molecular research tools that have been used to identify and compare several compounds. Proteins are one of the major molecules of interest within mitochondria, because their disturbance is directly responsible for several biologic modulations. Proteomics is the study of all proteins at a single given moment; it involves tools to identify and elicit the entire protein composition of a single tissue, cell or organelle (Wilkins et al., 1996). Proteomic tools have developed steadily, and each has been used in its time in mitochondrial proteome research, starting with the classic combination of IEF (isoelectric focusing) and SDS-PAGE (sodium dodecyl sulfate polyacrylamide gel electrophoresis) known as 2-DE (two-dimensional electrophoresis). Next came the DIGE (Differential Gel Electrophoresis) fluorescent method, and now tools include several gel-free (MudPIT) and novel peptide labeling techniques, in addition to complementary functional analysis methods (e.g. Blue Native and Native DIGE).

The analysis of cell compartments and specific organelles has become more common among proteomics researchers, now that subcellular research has provided in-depth knowledge of specific cellular signaling and other related functions (Scheffler, 2008). Up to now, mitochondria have been one of the main organelles to be investigated with a wide range of 
research tools (Lopez \& Melov, 2002), which have generated valuable molecular data (Scheffler, 2008). The main interest driving mitochondrial research stems from the wide spectrum of important molecular signaling that this organelle performs within the cell and also the entire organism, including its crucial role in energy production (Ernster \& Schatz, 1981), calcium homeostasis (Deluca et al., 1962), programmed cell apoptosis (Liu et al., 1996) and several pathologies (Chan, 2006; Pagliarini et al., 2008). Furthermore, mitochondrial dysfunction may play a crucial role in neurological (e.g. Alzheimer's, Parkinson's) (Lovell et al., 2005; Jones, 2010), cardiovascular (e.g. Ischemia, heart failure) and muscular diseases (Kim et al., 2006; Finsterer \& Stollberger, 2010), as well as in the development of cancer (Kamp et al., 2011) and aging processes (Dencher et al., 2007; O'Connell \& Ohlendieck, 2009).

It is also known that the mitochondrion network within a multicellular organism may be coordinated by a proteome reservoir of thousands of polypeptides $(\sim 1500)$, which can be up or down-regulated and have not been fully covered until now (Meisinger et al., 2008). Therefore the cataloging of the entire organelle proteome is of inestimable value to biomedical research, and further understanding of molecular mitochondrial modulation of positive stimulus or pathological insults shows enormous pharmacological potential (Fearnley et al., 2007; Wang et al., 2009). By different proteomic methods, much progress has been made in this direction in order to target and catalogue mitochondrial proteins from different organisms, such as humans (Rabilloud et al., 1998; Lefort et al., 2009), rodents (Zhang et al., 2008; Doran et al., 2009), fungi (Grinyer et al., 2004) and plants (Taylor et al., 2011).

In addition to simple proteome cataloging, several studies have been carried out to compare mitochondrial proteomes from different tissues (Forner et al., 2006; Fang \& Lee, 2009; Forner et al., 2009), as well as from organ structures (e.g. heart atria, ventricle) (Forner et al., 2009) and mitochondrial subpopulations (e.g. intermyofibrillar and subsarcolemmal) (Kavazis et al., 2009; Ferreira et al., 2010; Ferreira et al., 2010), with the aim of characterizing specific molecular profiles and functions. Using these tissues, specific proteome characterization during various biologic stimuli and disturbances, such as aging (Dencher et al., 2007; O'Connell \& Ohlendieck, 2009), exercise (Kavazis et al., 2009; Egan et al., 2011) and oxidative stress (2008; Lee et al., 2008; Zhang et al., 2008) have also been investigated to attempt to answer the numerous questions concerning the disturbance and adaptation of mitochondrial homeostasis.

Concerning the delicate process of organelle isolation and some proteomic analysis limitations, much has been achieved in surveying the mitochondrial proteome, as reviewed elsewhere (Mathy \& Sluse, 2008). Classic protein detection methods, such as 2$\mathrm{DE}$, have been improved. Moreover, other proteomical techniques have reached higher levels of accuracy; data collection has improved with sample labeling and gel-free analysis, such as shotgun proteomics performed by multidimensional chromatography (2D-LC-MS) directly coupled with high throughput mass spectrometry (Aebersold \& Mann, 2003; Tao et al., 2009). By means of these classic and up-to-date techniques, mitochondrial proteins have also been confirmed by the functional proteomic approach using native electrophoresis (e.g. Blue Native PAGE and Native DIGE) to investigate protein-protein interactions and membrane protein complexes (Brookes et al., 2002), increasing insights into molecular expression and signaling within inner and outer mitochondrial compartments. 


\subsection{Proteomic gel-based techniques in mitochondrial research}

The bulk of mitochondria proteome research has been performed using 2-DE associated with MS (mass spectrometry) identification. By combining IEF and protein separation by molecular mass (SDS-PAGE), after the staining process 2-DE gels may reveal up to 3000 protein spots (Lopez \& Melov, 2002). The capacity to simultaneously resolve thousands of proteins and by this technique compare different proteomes is possibly the main strength of this technique, which has undergone constant improvement since its invention in the middle of the 70's (Klose, 1975; O'Farrell, 1975). To overcome its various limitations, such as sample complexity, poor protein solubilizing (e.g. membrane proteins) and low resolution (e.g. hydrophobic and extreme acid or basic proteins) observed in 2-DE analyses, several upgrades have been developed, from sample preparation (e.g. protein extraction and solubilizing process) to gel conduction. Given the precision needed in mitochondrial proteomic analysis, these limitations represent a considerable barrier. Marty and Sluse (2008) reported that mitochondrial proteins appear mostly within the $\mathrm{pH}$ range of 3 to 11 , and within the 15 to $100 \mathrm{kDa}$ molecular mass range. Furthermore, several proteins from the electron transporter chain, which represent about $40 \%$ of inner membrane proteins (Schwerzmann et al., 1986), have high hydrophobic properties, a property that clearly makes IEF processes more difficult (Santoni et al., 2000). An incomplete proteome map may reflect a series of misconducted analyses and slightly erroneous insights, leading overall to a very poor understanding of mitochondrial processes.

Moving on from the classic gel-based technique, the limitations positively promoted a series of upgrades in proteomic methods, leading mitochondriomics research to provide more accurate, qualitative, quantitative and functional proteome data. Development of several fluorescent staining methods and protein labeling prior to 2-DE separation as performed by the Difference Gel Electrophoresis method, known as DIGE (Unlu et al., 1997), responded to specific concerns about the qualitative and quantitative limitations of protein spot detection. The DIGE method is based on the incorporation of different fluorescent cyanide dyes (Cydye3, Cydye5 and Cydye7 by GE Healthcare) into lysine residue present in the protein samples (Byrne et al., 2009). Once each sample is labeled with a distinct fluorescent dye, which includes an internal standard (a mixture of all labeled samples), samples are resolved together by the same 2-DE experiment. As the gel is scanned, fluorescent excitation from each distinct dye is captured and overlapped for spot expression comparison between the other dyes and the standard signal, enabling the results to overcome possible intra-gel variability errors (Lilley \& Friedman, 2004). In comparison to classic 2-DE, the DIGE technique has been successfully used by various research groups to shed some light on the mitochondrial proteome in a wide variety of organisms and physiological modulations (Jacoby et al., 2010; Egan et al., 2011; Glancy \& Balaban, 2011). Because it overcomes the problem of data reproducibility, DIGE is the ultimate gel-based method and strongly recommended when protein quantification and comparison is desirable, as has been well reviewed (Mathy \& Sluse, 2008).

Most of the gel-based methods (2-DE and DIGE) started with treatments using strong solubilizing detergents (e.g. SDS, CHAPS, Sulfobetaines, Triton- $X$ ) and chaotropic agents (e.g Urea, Thiourea) as reviewed by Petriz et al., (2011). The use of such agents leads to a real limitation on gel-based analysis caused by denaturing processes, which prevent any functional and protein-cross-talk analysis. However, major protein complexes present in abundance in the mitochondrial membrane may be analyzed from a functional perspective, 
as proposed by differential analyses, such as Blue-Native Electrophoresis (BN-PAGE) developed by Schagger and Von Jagow (1991). The main idea of BN-PAGE in mitochondrial research is first to separate membrane and other functional protein complexes by preserving enzyme activity using a non-denaturing gel. These entire complexes are then separated within a denaturating SDS-PAGE gel in order to divide protein complexes subunits by their molecular weight (Schagger \& von Jagow, 1991). Brookes et al. (2002) have shown the great potential that this technique has demonstrated in functional proteomics for mitochondrial molecular signaling, protein-to-protein interaction and post-translational modifications, especially in respiratory chain proteins from the mitochondrial membrane. A variation of 2D BN-PAGE is the Native DIGE (Difference Gel Electrophoresis) technique (Dani \& Dencher, 2008), which couples the fluorescent dyes labeling technique to the previously described BN-PAGE (Dani \& Dencher, 2008). DIGE analyses use fluorescent labeling and internal standards to enhance the accuracy of analyses. Thus, non-denaturing techniques have been well used (van den Ecker et al., 2010; Phillips et al., 2011), demonstrating that these techniques may contribute extensively to greater knowledge on the part that molecular signaling plays in mitochondrial functionality.

\subsection{Gel-free and proteomic straightforward methods}

Up-to-date gel-free proteomic techniques, such as LC/LC-MSMS (Reinders \& Sickmann, 2007; Lefort et al., 2009) have complemented gel-based experiments, leading mitochondrial molecular investigation to higher levels of data production and accuracy. It is well known that protein quantitation and low abundant protein detection have been among the major limitations on proteomic research. Fortunately, a series of gel-free methods have empowered this research by overcoming some of the main in-gel limitations and functioning as complementary tools for proteomic data mining. Gel-free methods are based on the separation of complex protein samples by liquid chromatography (e.g. reversed-phase, strong cationic exchange) followed by direct mass spectrometry analysis. When performed by more than one LC column this entire process characterizes 2D-LC analysis, known as multidimensional protein identification technology (MudPIT) (Link et al., 1999). MudPIT has been recognized as a high throughput method with enhanced ability to identify thousands of proteins within a single experiment (Motoyama \& Yates, 2008). To enhance multidimensional chromatography for MS analysis, a series of chemical molecular labeling methods were developed to facilitate proteomic mining and especially quantitative proteome comparisons. Basically, different proteome samples are mixed with isobaric or stable isotope chemical tags, digested with proteolytic enzymes such as trypsin and then loaded together into MudPIT, enabling quantitative comparisons (Aebersold \& Mann, 2003).

ICAT (Isotope-Coded Affinity Tags), SILAC (Stable Isotope Labeling with Amino acids in Cell culture) and iTRAQ (Isobaric Tags for Relative and Absolute Quantitation) are the main quantitative-labeling methods for gel-free methodology, permitting comparisons between different samples ( 2 to $\sim 4$ ) within the same experiment, as well as increasing the amount of quantitative proteome data that can be gathered by making the final process of peptide MS identification easier (Lovell et al., 2005; Jin et al., 2007; Meany et al., 2007). Each of these labeling techniques has its own peculiarity; for instance, the SILAC method is based on the incorporation of "light" or "heavy" isotope agents $\left({ }^{2} \mathrm{H},{ }^{13} \mathrm{C},{ }^{15} \mathrm{~N}\right)$ within distinct cell cultures, which will further synthetize labeled proteins for proteomic comparisons. SILAC was first 
described by Ong et al., (2002) to quantify protein expression differences from mammalian cells through a differentiation process. This method is also known as metabolic stableisotope labeling and has been used to investigate thousands of mitochondrial proteins identified by a variety of studies in pathology, such as Parkinson's treatment (Jin et al., 2007), human cytomegalovirus infection (Zhang et al., 2011) and diabetic sensory neuropathy etiology (Akude et al., 2011).

Another well-established labeling method, ICAT, was first described by Gygi et al., (1999) to quantify proteome modulation of yeast metabolic function under glucose-repressed stimulus. The ICAT technique labels cysteine (Cys) side chains with "light" or "heavy" isotope tags, permitting intensity pair comparison from peptide ions from distinctly labeled protein samples. This labeling technique has also been well implemented in mitochondrial analysis (Jiang et al., 2005; Lovell et al., 2005), but ICAT fails to identify non-cysteinecontaining proteins, which is its major technical limitation.

A vital property of gel-free methods (2D-MSMS) is the generation of a great number of MS spectra, which may be further quantified by several peptide tagging methods (e.g. ICAT, SILAC, iTRAQ). Nevertheless, the identification and analysis of proteins from marked peptide spectra is usually time-consuming. Overcoming this limitation, the ultimate labeling method is iTRAQ, which has made the entire process less laborious. Another major improvement brought by this method is the ability to analyze up to four different protein samples in the same experiment, leading to a single MS spectrum peak (Ross et al., 2004). By labeling the peptides' N-termini iTRAQ is a successful tool in mitochondrial proteome development, principally within quantitation research design (Jullig et al., 2007; Kavazis et al., 2009; Glancy \& Balaban, 2011). Gel-based and gel-free methods for mitochondrial analysis are schematically represented in Figure 2. Undoubtedly, mitochondrial proteomic research still leaves several gaps. It is clear that the classic proteomic approach alone will not be enough to fill these gaps. The two strategies together are likely to be the most complete and secure path to successful mitochondrial proteome research.

\section{Proteomic tools applied to understanding mitochondria: The effects of drugs}

The mitochondrion plays a key role in normal and healthy cells. However, under abnormal conditions this organelle can also be involved in cell dysfunction and death. Mitochondrial dysfunction may be implicated in a large number of diseases, such as cancer, neurodegenerative diseases (such as Alzheimer's), diabetes, ischemia-reperfusion injury and aging (Wallace, 1999). The identification of mitochondrial proteins may therefore be a beneficial tool in drug development and also to diagnose targets for such diseases. The treatment of these illnesses involves the drug-mitochondrial interaction that acts in the three main mitochondrial functions: energy production, reactive oxygen species fabrication, and cell death control via both apoptotic and necrotic pathways (Green \& Reed 1998; Kristal \& Brown 1999). These organelles have a superoxide radical anion source, which arises from oxidative phosphorylation and can produce reactive oxygen species and also their precursors. Although protective mechanisms are known to regulate these molecular species, reversible and irreversible oxidative damage to proteins, nucleic acids and lipids may occur. Under elevated oxidative stress conditions, such as cell aging or disease, these oxidative lesions can be accumulated and have drastic consequences for cellular function, leading ultimately to senescence, environmental 


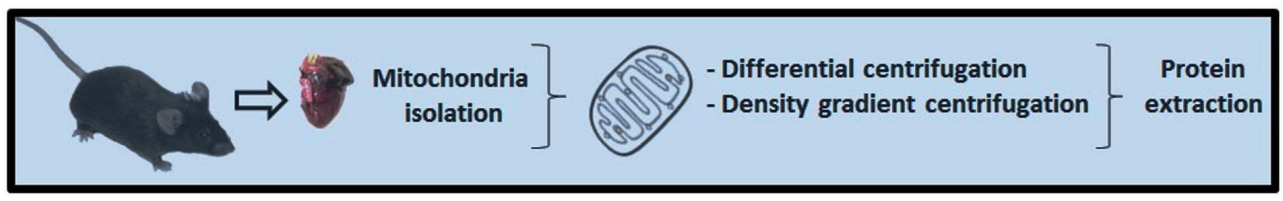

PROTEOMIC

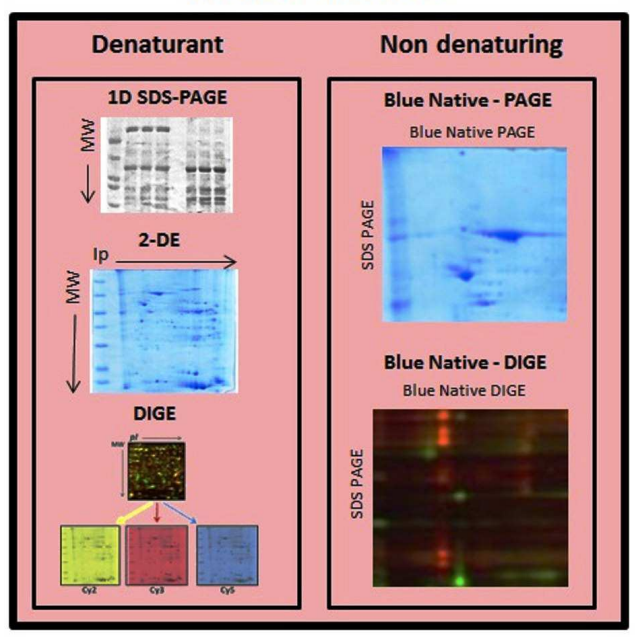

GEL FREE METHODS

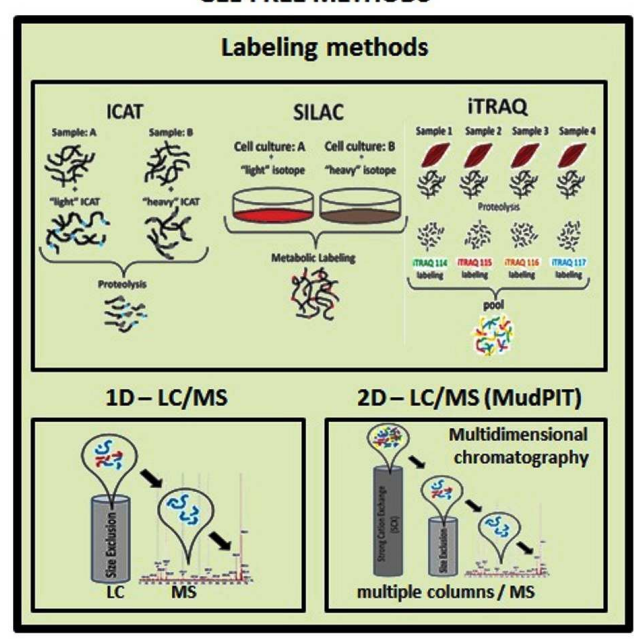

Fig. 2. Proteomic tools for mitochondrial analysis. Schematic workflow of the gel-based (red) and gel-free (green) proteomic tools used to compose the mitochondrial proteome after extraction process (blue).

modification, for example in the S-nitrosylation process or the oxidation of cysteine to sulfenic acid, and also to cell death (Gibson, 2004).

In this context, mitochondria are a pharmacological target for drugs that modulate oxidative stress (Murphy \& Smith, 2000). There are various compounds that can target oxidative stress in mitochondria. Coenzyme $\mathrm{Q}$ and vitamin $\mathrm{E}$ are natural compounds that are both used as dietary supplements. MitoQ and MitoVitE are based on triphenylphosphorium modifications of coenzyme $Q$ and vitamin E, respectively. They are more potent than their natural sources and have been suggested for treating Friedreich's ataxia, since they prevent cell death (Jauslin et al., 2003). Another pharmacological example is flupirtine, a nonopioid analgesic drug with mitochondrial antioxidant activity, which acts as a free radical scavenger (Schluter et al., 2000). Flupirtine has been shown to inhibit ischemic injury (Osborne et al., 1996) and apoptosis, and may be protective against Alzheimer's and prion disease (Perovic et al., 1998).

In spite of the role of mitochondria in different diseases and their potential target for some disease treatments, there is little information about the proteome associated with drugmitochondrial interaction and target biomarker drugs for treatment design. Based on proteome analysis, with 2D-gel analysis followed by MALDI TOF MS or ESI MS/MS for protein identification, Arrell et al., (2006) analyzed pharmacologically mimicked ischemic 
preconditioning. This pathology is characterized by resistance to ischemia reperfusion injury in response to previous short ischemic episodes. In this study, the authors mimicked preconditioning, treating isolated rabbit ventricular myocytes with adenosine or diazoxide. They observed a distinctive pattern of affected proteins consistent with specific perturbation of mitochondrial metabolism through changes to a selected number of mitochondrial protein complexes, with specificity and complexity of the drug response. Compared to the vehicle-treated controls, expression of 28 significantly altered proteins was observed and 19 of them were identified. The majority of these proteins are involved in mitochondrial energetics, including subunits of enzymes from the tricarboxylic acid cycle and oxidative phosphorylation complexes. Among these changed proteins, the $\beta$-subunit of ATP synthase was adenosine-phosphorylated after $60 \mathrm{~min}$ of treatment. These results prove that adenosine and diazoxide treatment acts in different cell parts, especially in the mitochondria (Arrell et al., 2006).

Regarding the anti-inflammatory agents that target mitochondria, the proteome-related literature has reported some data about simvastatin. Simvastatin is a 3-hydroxy-3methylglutaryl coenzyme A reductase inhibitor that provides neuroprotection, acting against cell loss resulting from strokes (Law et al., 2003), Alzheimer's disease (Vega et al., 2003), Parkinson's disease (Rajanikant et al., 2007) and traumatic brain injury (Lu et al., 2004), all of which are pathologies that target mitochondria. In the same line, Pienaar et al., (2009) compared rat mitochondrial proteins pre-treated with simvastatin for 14 days, followed or not by a unihemispheric injection of a mitochondrial complex $\mathrm{S}$ inhibitor. The authors identified 24 different mitochondrial proteins by mass spectroscopy, which represented many facets of mitochondrial integrity, with most of them forming part of the electron transport chain machinery (Pienaar et al., 2009). These results demonstrated that the simvastatin-mitochondrial interaction may contribute to beneficial effects, especially when associated with statin use.

Research with cancer has shown that cancer cells are adapted to fast growth and proliferation in acid $\mathrm{pH}$ conditions and low oxygen tension (Griffiths, 2001). Cancer cells have a mitochondrial defect in oxidative phosphorylation, and this can be reversible. Therefore, mitochondrial-drug interaction in cancer pathology should divert energy production from the anaerobic path to oxidative phosphorylation. The effect is to decrease nuclear ATP, leading to a consequent reduction in cell proliferation, so that the tumor cells begin cellular differentiation and subsequently undergo cell death and apoptosis (Harris et al., 2000).

Neoplastic drugs that target different mitochondrial proteins are already on the market for the treatment of various types of cancer. One of these, doxorubicin, also known by the trademark name Adriamycn, is an anthracycline antibiotic and extremely effective antineoplastic agent used in a wide variety of solid cancers and hematological malignancies since the early 1960's (Di Marco et al., 1969). Hammer et al., (2010) analyzed proteomically the doxorubicin-induced changes in a hepatocellular carcinoma cell model, using 2D DIGE, liquid chromatography coupled with electrospray ionization and a hybrid quadrupole linear ion-trap and Fourier-transform ion-cyclotron-resonance mass spectrometry (LC-ESILTQ-FTICR-MS) and nano-LC coupled offline to MALDI-TOF/TOF-MS (LC-offlineMALDI-TOF-TOF-MS.) These methods identified 155 different proteins that could be assigned to a wide variety of biological processes, compared to non-treated control cells. Functional analysis revealed major influences of doxorubicin on proteins involved in 
protein synthesis, DNA damage control, electron transport/mitochondrial function and tumor growth.

Further, as regards mitochondrial proteins, the authors above observed that doxorubicin increases the Bax level (apoptosis regulator), which is involved in cytochrome $\mathrm{C}$ release from mitochondria and in turn caspase activation and decreased expression of Bcl-2. Oxidative stress induction was also shown by the enhanced levels of ferredoxin reductase and transferring receptor protein 1 and decreased levels of ERO1-like protein- $\alpha$. Proteins involved in $\beta$-oxidation, such as acyl-CoA dehydrogenase, acetyl-CoA carboxylase 1 and hydroxymethylglutaryl-CoA synthase, were also increased in the doxorubicin-treated group. These results demonstrated that application of doxorubicin led to up-regulation of proteins involved in adaptation to oxidative stress and maintenance of cell integrity (Hammer et al., 2010).

Doxorubicin is widely used in drug combination strategies for non-Hodgkin lymphoma therapy (Multani et al., 2001). Jiang, Sun et al., (2009) used 2D-DIGE in combination with ESI-MS/MS to analyze changes in mitochondrial protein expression in controlling Raji (lymphoblast-like cells) and doxorubicin-treated Raji cells. Defects in the mitochondrial antioxidant defense system, DNA repair, and oxidative phosphorylation may be the main mechanisms involved in the effect of doxorubicin on the mitochondria of Raji cells. Imperfections in the mitochondrial antioxidant defense system have dual effects on the anticancer mechanism and cardiac toxicity. The authors also found numerous proteins associated with significant chemo-resistance to doxorubicin, including heat shock protein (HSP) 70, prohibitin and ATP-binding cassette B6 transporter isoform. The reported results identified several biomarkers with the potential to enable prediction of anticancer therapy response (Jiang et al., 2009).

Another example of a highly potent chemotherapeutic drug that interacts with mitochondria is cisplatin, commonly used for a variety of human malignancies, such as testicular, prostate, ovarian, cervical, lung, and colon cancers (Wang \& Lippard, 2005). Cisplatin cytotoxicity is primarily mediated by its ability to cause DNA damage and apoptotic cell death (Siddik, 2003). Zhang et al., (2009) demonstrated, by different experimental methods, together with proteome analysis, that the induction of phospholipase A2-activating protein (PLAA) promoted cisplatin-associated apoptosis in cervical carcinoma HeLa cells by four pathways: activation of phospholipase A2 and accumulation of arachidonic acid, which causes mitochondrial damage; down-regulation of clusterin, a cytoprotective protein which promotes chemoresistance; upregulation of IL-32, which causes apoptosis in HeLa cells; and activation of JNK/c-jun signaling, which is an established inducer of Fas ligand expression and apoptosis mediated receptor (Zhang et al., 2009).

Analgesics also interact with mitochondria. The literature has reported the widely used analgesic acetaminophen and its mitochondrial interaction, including the fact that acetaminophen overdose may cause severe centrilobular hepatic necrosis in experimental animal models and humans (Davidson \& Eastham, 1966). Ruepp et al., (2002) explored acetaminophen overdose effects in mitochondria from animal model liver by genomic and proteomic tools. Proteomics showed that protein changes in mitochondria were present at 15 min post injection, thus preceding most of the gene regulations. The decrease in ATP synthase subunits and $\beta$-oxidation pathway proteins indicated a loss of energy production. Since mitochondrial morphology was also affected very early at top dose, they concluded that acetaminophen overdose was a direct action of its known reactive metabolite $\mathrm{N}$-acetyl$p$-benzoquinone imine, rather than a consequence of gene regulation (Ruepp et al., 2002). 
Antipsychotic drugs are another kind of medication that target mitochondria. Psychotic brains present anomalies in their mitochondria, including mitochondrial dysfunction or abnormal cerebral energy metabolism, which may play an important role in the pathophysiology of schizophrenia. Together with this, mitochondrial energy metabolism might be disturbed by the antipsychotic drugs used (Modica-Napolitano et al., 2003). Various antipsychotic drugs have been available for treatment: chlorpromazine (CPZ), was in the first generation and presents serious side-effects (Freedman, 2003); clozapine (CLZ), the first atypical antipsychotic drug to present more antipsychotic effects without the adverse mobility effects of the first-generation drugs (Freedman, 2003); and quetiapine (QTP), an atypical antipsychotic drug that usually acts on both dopamine receptors and serotonin receptors (Martorell et al., 2006). Comparative proteomics of all mitochondrial proteins from the cerebral cortex and hippocampus of a rat model (Sprague-Dawley rats) in response to CPZ, CLZ and QTP antipsychotic medication demonstrated 14 differentially expressed different proteins. Six of them belong to the respiratory electron transport chain of oxidative phosphorylation, showing significant changes in protein quantity including NADH dehydrogenase $1 \alpha$ subcomplex 10, NADH dehydrogenase flavoprotein 2, NADH dehydrogenase Fe-S protein 3, F1-ATPase beta subunit, ATPase, $\mathrm{H}^{+}$ transporting, lysosomal, beta $56 / 58 \mathrm{kDa}$, isoform 2 and ATPase, $\mathrm{H}^{+}$transporting, V1 subunit A, isoform 1; demonstrating antipsychotic drug-mitochondrial interaction (Ji et al., 2009).

Dietary supplements can also act on the mitochondrial proteome. Epidemiological studies suggested that the consumption of soy-containing foods has the ability to prevent or to slow down the development of cardiovascular syndromes (Zhang. X, 2003). A systematic review suggested that a diet supplemented with soy protein isolate containing isoflavones reduces low-density lipoprotein (LDL) and cholesterol (critical risk factor in the development of cardiovascular disease), but no effects on triglycerides or high-density lipoprotein cholesterol contents were observed (Cassidy \& Hooper, 2006). Proteome analysis revealed that the LDL-induced alterations of numerous proteins were reversed by the soy extracts and also by the combination of genistein/daidzein soy isoflavones. However, both treatments regulated only three proteins functionally linked to mitochondrial dysfunction and were also connected to reducing the generation of oxidized-LDL-mediated mitochondrial reactive oxygen species, which could induce damages.

Several reports demonstrate the role of specific foods in mitochondrial function (Fuchs. D et al., 2007). A nutrient-sensing target of the rapamycin pathway appears to have a conserved role in regulating life span. It has been demonstrated that the reduced nutrient-sensing target of rapamycin signaling extends yeast's chronological life-span by increasing mitochondrial oxygen consumption, in part by up-regulating mtDNA-encoded oxidative phosphorylation subunit translation (Bonawitz et al., 2007). These data demonstrate that mitochondrial dysfunction could also be related to aging. Besides, it has been demonstrated by 2 D DIGE and MALDI MS/MS that the nutrient-sensing target of rapamycin signaling has a global role in regulating mitochondrial proteome dynamics and function (Pan \& Shadel, 2009).

Another proteomic field that improved the understanding of drug-mitochondria interaction is in the elucidation of drug targets and the discovery of mechanisms of resistance to different pathogens. Plasmodium falciparum is responsible for approximately 247 million cases of malaria and one million deaths each year (WHO, 2011). The drug doxycycline is currently one of the recommended chemoprophylactic regimens for 
travellers visiting malaria-endemic areas in southeast Asia, Africa and South America (Gras et al., 1993). The emergence of P. falciparum resistance to most anti-malarial compounds has highlighted the urgency to develop novel drugs and to clarify the mechanisms of anti-malarial medications currently used. In this study, the authors analyzed protein expression changes by 2D-DIGE and iTRAQ methods in the schizont stage of the malarial parasite, following doxycycline treatment. Although some of these proteins have already been described as being deregulated by other drug treatments (Lasonder et al., 2008), numerous modifications in protein levels seem to be specific to doxycycline treatment, suggesting that apicoplasts and mitochondria are the main targets of doxycycline (Briolant et al., 2010).

Despite the progress made in these combined efforts, human mitochondrial databases have not yet been fully exploited to identify or target new candidates for drug development. In addition, the proteome of different pathologies and also the interaction between drugpathology proteins related to pharmacological action and side effects should be further studied. On the other hand, proteomic tools can help to understand this important protein relation better, with a view to designing mitochondrial biomarkers that may be useful in drug screening, clinical diagnosis, treatment follow-up and in discovering mechanisms of drug resistance (Figure 3).

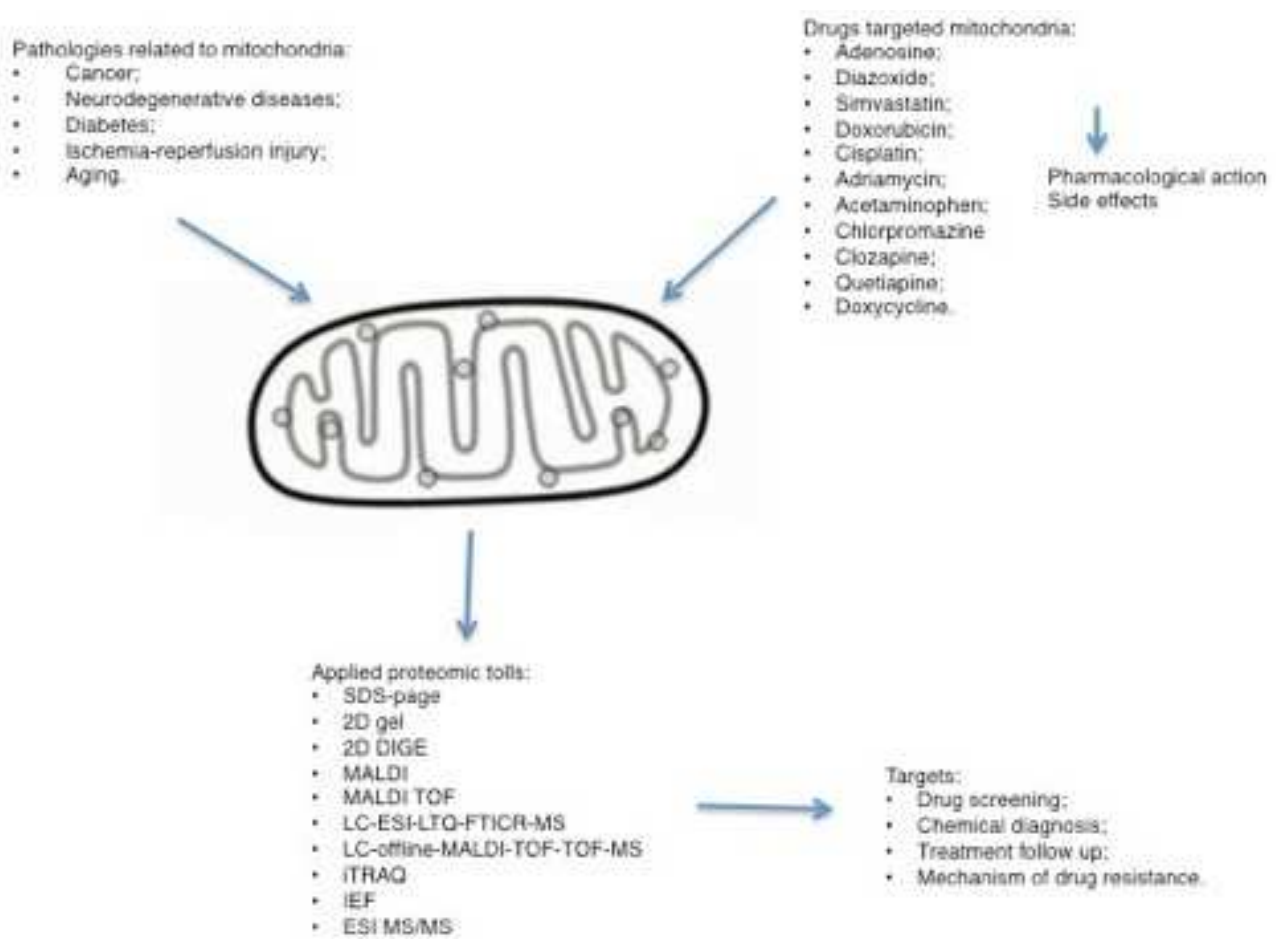

Fig. 3. Summary of main pathologies and drugs related to mitochondria, together with the main proteomic tools described in the studies above, as well as the proposed targets of this triple association. 


\section{Mitochondrial proteomics applied to exercise research}

As reviewed by Lopez and Melov (2002), several studies have shown the characterization of complex mixtures of mitochondria proteins expressed in diseased and healthy samples, leading to a further understanding of their functions in metabolic or physiological processes. This approach has reinforced protein research, leading to important progress in the study of mitochondrial functions and cognate molecular signaling. It is well known that exercise leads to biological adaptations that are highly specific and directly dependent on duration, frequency, intensity and stimulus nature, leading this process to require intensified oxygen demand (Hawley et al., 2011). As is recognized, one of the most important contributions of mitochondria is ATP synthesis, through oxidative phosphorylation (OXPHOS). Therefore, it seems obvious that a large range of decisive phenotype modulations associated with exercise occur within mitochondria. Despite the great importance of the mitochondrial proteome in several physiologic adaptations, there are few data and many questions remaining vis-à-vis molecular signaling, interaction and activity following exercise stimulus.

In this perspective, Bo, Zhang and Ji (2010) indicated that exercise not only raises mitochondrial OXPHOS, but also exerts profound influences on mitochondrial morphology and biogenesis, being one of the most important influences on the fusion-fission process, whose action is responsible for continuous mitochondrial morphology remodeling. The mitochondrion has been seen as a dynamic networking organelle in which fusion and fission are intrinsic coupled processes. This process supports deletions of animals' damaged mitochondria according to organelle size (Kowald \& Kirkwood, 2011). The complete process of mitochondrial fusion-fission has not been thoroughly elucidated, however, because there are many proteins involved in execution or modulation that remain to be described. Nevertheless, the mitochondrial dynamic appears to be specifically regulated depending on cell type or by the given function of certain tissues (Liesa et al., 2009). Mitochondrial fusion is a mechanical two-step process, where the outer and inner mitochondrial membranes are fused. This process depends on membrane potential and also the presence of GTP molecules, and is coordinated by optic atrophy gene 1 (OPA1) and mitofusins (Mfns), which promote the fusion of the lipid membrane (Liesa et al., 2009; Zorzano, 2009; Otera \& Mihara, 2011). These proteins carry out various activities in promoting fusion and modulating the mitochondrial membrane (Zorzano, 2009). Moreover, according to the same author, fission is coordinated by dynamin-related protein 1 (Drp1) and Fission 1 homologue protein (Fis1) that completes these events.

Mitochondrial dynamics plays an important role in organelle functionality, contributing to an efficient bioenergy supply. The interruption of such processes leads to loss of mitochondrial activity and further diminished OXPHOS, suggesting its essentiality for mitochondrial function (Misko et al., 2010; Kowald \& Kirkwood, 2011) and its contribution to the development of some neurodegenerative diseases (Westermann, 2010). Dynamic modifications in mitochondrial fusion-fission proteins during a session of extended exercise with incremental duration leads to a decrease in mitofusin Mfn1/2 expression and also an increase in Fis1 expression (Bo et al., 2010). According to the same authors, these alterations are related to exercise intensity, suggesting that fission may play a compensatory role for OXPHOS injury through improving glucoses and pyruvate uptake. This fact could maintain energy supply and prevent lactate accumulation, delaying the fatigue process associated with the enhancement of $\mathrm{H}^{+}$concentration. So it is 
possible that in severe exercise mitochondrial fission may be a powerful indicator of muscle damage (Bo et al., 2010).

The role of exercise in cardiac health promotion has been well described in literature (Ascensao et al., 2007). This cardioprotective phenotype, normally associated with endurance exercise, seems to be related to increased myocardial antioxidant capacity (Kavazis et al., 2009). Oxidative stress resulting from exercise seems to be part of physiological adaptation. Severe exercise intensities activate a cascade of intracellular sources for reactive oxygen species (ROS) and it is clear that muscle adaptation depends on this process. However, it is important to observe that excessive ROS production can negatively influence exercise performance and can also lead to long-term health consequences (Bailey et al., 2004; Sahlin et al., 2010; Sun et al., 2010). The mechanism of increased ROS production during exercise is not totally clear, but experimental evidence suggests that mitochondria are the main source of ROS production during exercise (Di Meo \& Venditti, 2001; Fernstrom et al., 2007). ROS levels are also described as depending on oxygen concentrations, and an additional electron accepted during energy production is used to create superoxide, a more reactive form of oxygen, which can be converted to hydrogen peroxide $\left(\mathrm{H}_{2} \mathrm{O}_{2}\right)$ (Sarsour et al., 2009). Animal cells have additional antioxidant enzymes (e.g. catalase, glutathione peroxidase), and the newly identified family of peroxidases (e.g. PRDX) to neutralize $\mathrm{H}_{2} \mathrm{O}_{2}$ (Chang et al., 2004). Peroxidases are a family with at least six isoforms in mammalian cells. One of these is the mitochondrion-specific isoform, PRDXIII, which acts in defense against oxidative stress caused by $\mathrm{H}_{2} \mathrm{O}_{2}$ produced during the mitochondrial respiratory chain process (Kavazis et al., 2009). By using the iTRAQ technique, Kavazis et al., (2009) demonstrated a left ventricular remodeling after endurance exercise training in preconditioned animals. This study has shown the upregulation of PRDXIII in subsarcolemmal mitochondrial subfraction, demonstrating a possible role of PRDXIII in heart remodeling. Exercise has also been demonstrated to reduce oxidative stress and dysfunction of mitochondria after myocardial infarction.

ATP production is well described as declining with age (Drew \& Leeuwenburgh, 2003; Drew et al., 2003; Short, 2005) leading to metabolic impairment, so endurance exercise seems to be an important agent in improving and preserving mitochondrial function. Using mass spectrometry methods and the iTRAQ approach, Lanza et al., (2008) demonstrated that tricarboxylic cycle enzymes and electron transport protein expression were down-regulated in older sedentary people when compared to younger subjects. On the other hand, endurance-trained elderly men exhibited an up-regulation of those proteins, suggesting that the expression level of key mitochondrial proteins may be a primary determinant for ageing. Thus, diminished oxidative capacity and regular endurance exercise appear to be beneficial in improving ATP synthesis, partially reversing some metabolic impairment caused by aging. Recently, Egan et al., (2011) used the 2-D DIGE technique to demonstrate that adaptation of skeletal muscle to endurance exercise occurs within only 7 days of training with an increase in ATP generation.

Exercise is therefore recognized as an important agent in improving health, and it is also an auxiliary in numerous medical treatments and therapy. These findings about exercise have led to a better perception of the plasticity of skeletal muscle, mainly by the modulation of the mitochondrial proteome, contributing to understand muscle sensitivity to exercise stimulus. All of these results obviously indicate that phenotype changes associated with exercise are linked directly to mitochondrial proteome modulation. This fact makes mitochondrial research a promising field in sports and medical science. 


\section{Conclusion}

In summary, data reported here clearly show the enormous importance of mitochondria in multiple processes such as drug metabolism and exercise. These processes could be better understood by the use of genomic and proteomic techniques, which are constantly improving. In this view, the use of such technologies could bring real benefits in physiological understanding and in the improvement of biotechnological research related to drug design and activity.

\section{References}

Aebersold, R. \& Mann, M. (2003). "Mass spectrometry-based proteomics." Nature 422(6928): 198-207.

Akude, E., Zherebitskaya, E., Chowdhury, S.K., Smith, D.R., Dobrowsky, R.T. \& Fernyhough, P. (2011). "Diminished superoxide generation is associated with respiratory chain dysfunction and changes in the mitochondrial proteome of sensory neurons from diabetic rats." Diabetes 60(1): 288-297.

Alberts Bruce, A.J., Julian Lewis, Martin Raff, Keith Roberts, and Peter Walter. (2002). Molecular Biology of the Cell. New York, Garland Science.

Arrell, D.K., Elliott, S.T., Kane, L.A., Guo, Y., Ko, Y.H., Pedersen, P.L., Robinson, J., Murata, M., Murphy, A.M., Marban, E. \& Van Eyk, J.E. (2006). "Proteomic analysis of pharmacological preconditioning: novel protein targets converge to mitochondrial metabolism pathways." Circ Res 99(7): 706-714.

Ascensao, A., Ferreira, R. \& Magalhaes, J. (2007). "Exercise-induced cardioprotection-biochemical, morphological and functional evidence in whole tissue and isolated mitochondria." Int J Cardiol 117(1): 16-30.

Bailey, D.M., Young, I.S., McEneny, J., Lawrenson, L., Kim, J., Barden, J. \& Richardson, R.S. (2004). "Regulation of free radical outflow from an isolated muscle bed in exercising humans." Am J Physiol Heart Circ Physiol 287(4): H1689-1699.

Bo, H., Zhang, Y. \& Ji, L.L. (2010). "Redefining the role of mitochondria in exercise: a dynamic remodeling." Ann N Y Acad Sci 1201: 121-128.

Bonawitz, N.D., Chatenay-Lapointe, M., Pan, Y. \& Shadel, G.S. (2007). "Reduced TOR signaling extends chronological life span via increased respiration and upregulation of mitochondrial gene expression." Cell Metab 5(4): 265-277.

Briolant, S., Almeras, L., Belghazi, M., Boucomont-Chapeaublanc, E., Wurtz, N., Fontaine, A., Granjeaud, S., Fusai, T., Rogier, C. \& Pradines, B. (2010). "Plasmodium falciparum proteome changes in response to doxycycline treatment." Malar J 9: 141.

Brookes, P.S., Pinner, A., Ramachandran, A., Coward, L., Barnes, S., Kim, H. \& DarleyUsmar, V.M. (2002). "High throughput two-dimensional blue-native electrophoresis: a tool for functional proteomics of mitochondria and signaling complexes." Proteomics 2(8): 969-977.

Byrne, J.C., Downes, M.R., O'Donoghue, N., O'Keane, C., O'Neill, A., Fan, Y., Fitzpatrick, J.M., Dunn, M. \& Watson, R.W. (2009). "2D-DIGE as a strategy to identify serum markers for the progression of prostate cancer." J Proteome Res 8(2): 942-957.

Camara, A.K., Bienengraeber, M. \& Stowe, D.F. (2011). "Mitochondrial approaches to protect against cardiac ischemia and reperfusion injury." Front Physiol 2: 13.

Cassidy, A. \& Hooper, L. (2006). "Phytoestrogens and cardiovascular disease." $\mathrm{J} \mathrm{Br}$ Menopause Soc 12(2): 49-56. 
Chan, D.C. (2006). "Mitochondria: dynamic organelles in disease, aging, and development." Cell 125(7): 1241-1252.

Chang, T.S., Cho, C.S., Park, S., Yu, S., Kang, S.W. \& Rhee, S.G. (2004). "Peroxiredoxin III, a mitochondrion-specific peroxidase, regulates apoptotic signaling by mitochondria." J Biol Chem 279(40): 41975-41984.

Chipuk, J.E., Bouchier-Hayes, L. \& Green, D.R. (2006). "Mitochondrial outer membrane permeabilization during apoptosis: the innocent bystander scenario." Cell Death Differ 13(8): 1396-1402.

Dani, D. \& Dencher, N.A. (2008). "Native-DIGE: a new look at the mitochondrial membrane proteome." Biotechnol J 3(6): 817-822.

Davidson, D.G. \& Eastham, W.N. (1966). "Acute liver necrosis following overdose of paracetamol." Br Med J 2(5512): 497-499.

Deluca, H.F., Engstrom, G.W. \& Rasmussen, H. (1962). "The action of vitamin D and parathyroid hormone in vitro on calcium uptake and release by kidney mitochondria." Proc Natl Acad Sci U S A 48: 1604-1609.

Dencher, N.A., Frenzel, M., Reifschneider, N.H., Sugawa, M. \& Krause, F. (2007). "Proteome alterations in rat mitochondria caused by aging." Ann N Y Acad Sci 1100: 291-298.

Di Marco, A., Gaetani, M. \& Scarpinato, B. (1969). "Adriamycin (NSC-123,127): a new antibiotic with antitumor activity." Cancer Chemother Rep 53(1): 33-37.

Di Meo, S. \& Venditti, P. (2001). "Mitochondria in exercise-induced oxidative stress." Biol Signals Recept 10(1-2): 125-140.

Doran, P., Donoghue, P., O'Connell, K., Gannon, J. \& Ohlendieck, K. (2009). "Proteomics of skeletal muscle aging." Proteomics 9(4): 989-1003.

Drew, B. \& Leeuwenburgh, C. (2003). "Method for measuring ATP production in isolated mitochondria: ATP production in brain and liver mitochondria of Fischer-344 rats with age and caloric restriction." Am J Physiol Regul Integr Comp Physiol 285(5): R1259-1267.

Drew, B., Phaneuf, S., Dirks, A., Selman, C., Gredilla, R., Lezza, A., Barja, G. \& Leeuwenburgh, C. (2003). "Effects of aging and caloric restriction on mitochondrial energy production in gastrocnemius muscle and heart." Am J Physiol Regul Integr Comp Physiol 284(2): R474-480.

Egan, B., Dowling, P., O'Connor, P.L., Henry, M., Meleady, P., Zierath, J.R. \& O'Gorman, D.J. (2011). "2-D DIGE analysis of the mitochondrial proteome from human skeletal muscle reveals time course-dependent remodelling in response to 14 consecutive days of endurance exercise training." Proteomics 11(8): 1413-1428.

Ernster, L. \& Schatz, G. (1981). "Mitochondria: a historical review." J Cell Biol 91(3 Pt 2): 227s255 s.

Fang, X. \& Lee, C.S. (2009). "Proteome characterization of mouse brain mitochondria using electrospray ionization tandem mass spectrometry." Methods Enzymol 457: 49-62.

Fearnley, I.M., Carroll, J. \& Walker, J.E. (2007). "Proteomic analysis of the subunit composition of complex I (NADH:ubiquinone oxidoreductase) from bovine heart mitochondria." Methods Mol Biol 357: 103-125.

Fernstrom, M., Bakkman, L., Tonkonogi, M., Shabalina, I.G., Rozhdestvenskaya, Z., Mattsson, C.M., Enqvist, J.K., Ekblom, B. \& Sahlin, K. (2007). "Reduced efficiency, but increased fat oxidation, in mitochondria from human skeletal muscle after 24-h ultraendurance exercise." J Appl Physiol 102(5): 1844-1849.

Ferreira, J.C., Bacurau, A.V., Bueno, C.R., Jr., Cunha, T.C., Tanaka, L.Y., Jardim, M.A., Ramires, P.R. \& Brum, P.C. (2010). "Aerobic exercise training improves Ca2+ 
handling and redox status of skeletal muscle in mice." Exp Biol Med (Maywood) 235(4): 497-505.

Ferreira, R., Vitorino, R., Alves, R.M., Appell, H.J., Powers, S.K., Duarte, J.A. \& Amado, F. (2010). "Subsarcolemmal and intermyofibrillar mitochondria proteome differences disclose functional specializations in skeletal muscle." Proteomics 10(17): 3142-3154.

Finsterer, J. \& Stollberger, C. (2010). "Cardiac manifestations of mitochondrial disorders." Eur J Heart Fail 12(6): 637; author reply 637-638.

Forner, F., Foster, L.J., Campanaro, S., Valle, G. \& Mann, M. (2006). "Quantitative proteomic comparison of rat mitochondria from muscle, heart, and liver." Mol Cell Proteomics 5(4): 608-619.

Forner, F., Kumar, C., Luber, C.A., Fromme, T., Klingenspor, M. \& Mann, M. (2009). "Proteome differences between brown and white fat mitochondria reveal specialized metabolic functions." Cell Metab 10(4): 324-335.

Frederick, R.L. \& Shaw, J.M. (2007). "Moving mitochondria: establishing distribution of an essential organelle." Traffic 8(12): 1668-1675.

Freedman, R. (2003). "Schizophrenia." N Engl J Med 349(18): 1738-1749.

Fuchs. D, Dirscherl. B, Schroot. J.H, Daniel. H \& Wenzel. U (2007). "Proteome analysis suggests that mitochondrial dysfunction in stressed endothelial cells is reversed by a soy extract and isolated isoflavones. ." J.Proteome.Res. 6: 2132-2142.

Gibson, B.W. (2004). "Exploiting proteomics in the discovery of drugs that target mitochondrial oxidative damage. ." Sci.Aging Knowledge.Environ. 12.

Glancy, B. \& Balaban, R.S. (2011). "Protein composition and function of red and white skeletal muscle mitochondria." Am J Physiol Cell Physiol 300(6): C1280-1290.

Gras, C., Laroche, R., Guelain, J., Martet, G., Merlin, M., Pottier, G., Guisset, M. \& Touze, J.E. (1993). "[Current role of doxycycline in the chemoprophylaxis of Plasmodium falciparum malaria]." Bull Soc Pathol Exot 86(1): 52-55.

Gray, M.W., Burger, G. \& Lang, B.F. (1999). "Mitochondrial evolution." Science 283(5407): 1476-1481.

Griffiths, J.R. (2001). "Causes and consequences of hypoxia and acidity in tumour microenvironments." Bioessays 23(3): 295-296.

Grinyer, J., McKay, M., Herbert, B. \& Nevalainen, H. (2004). "Fungal proteomics: mapping the mitochondrial proteins of a Trichoderma harzianum strain applied for biological control." Curr Genet 45(3): 170-175.

Gygi, S.P., Rist, B., Gerber, S.A., Turecek, F., Gelb, M.H. \& Aebersold, R. (1999). "Quantitative analysis of complex protein mixtures using isotope-coded affinity tags." Nat Biotechnol 17(10): 994-999.

Hammer, E., Bien, S., Salazar, M.G., Steil, L., Scharf, C., Hildebrandt, P., Schroeder, H.W., Kroemer, H.K., Volker, U. \& Ritter, C.A. (2010). "Proteomic analysis of doxorubicininduced changes in the proteome of HepG2cells combining 2-D DIGE and LCMS/MS approaches." Proteomics 10(1): 99-114.

Harris, M.H., Vander Heiden, M.G., Kron, S.J. \& Thompson, C.B. (2000). "Role of oxidative phosphorylation in Bax toxicity." Mol Cell Biol 20(10): 3590-3596.

Hawley, J.A., Burke, L.M., Phillips, S.M. \& Spriet, L.L. (2011). "Nutritional modulation of training-induced skeletal muscle adaptations." J Appl Physiol 110(3): 834-845.

Herrmann, J.M. \& Neupert, W. (2000). "Protein transport into mitochondria. ." Curr Opin Microbiol 3 (2): 210-214.

Jacoby, R.P., Millar, A.H. \& Taylor, N.L. (2010). "Wheat mitochondrial proteomes provide new links between antioxidant defense and plant salinity tolerance." J Proteome Res 9(12): 6595-6604. 
Jauslin, M.L., Meier, T., Smith, R.A. \& Murphy, M.P. (2003). "Mitochondria-targeted antioxidants protect Friedreich Ataxia fibroblasts from endogenous oxidative stress more effectively than untargeted antioxidants." FASEB J 17(13): 1972-1974.

Ji, B., La, Y., Gao, L., Zhu, H., Tian, N., Zhang, M., Yang, Y., Zhao, X., Tang, R., Ma, G., Zhou, J., Meng, J., Ma, J., Zhang, Z., Li, H., Feng, G., Wang, Y., He, L. \& Wan, C. (2009). "A comparative proteomics analysis of rat mitochondria from the cerebral cortex and hippocampus in response to antipsychotic medications." J Proteome Res 8(7): 3633-3641.

Jiang, X.S., Dai, J., Sheng, Q.H., Zhang, L., Xia, Q.C., Wu, J.R. \& Zeng, R. (2005). "A comparative proteomic strategy for subcellular proteome research: ICAT approach coupled with bioinformatics prediction to ascertain rat liver mitochondrial proteins and indication of mitochondrial localization for catalase." Mol Cell Proteomics 4(1): 12-34.

Jiang, Y.J., Sun, Q., Fang, X.S. \& Wang, X. (2009). "Comparative mitochondrial proteomic analysis of Rji cells exposed to adriamycin." Mol Med 15(5-6): 173-182.

Jin, J., Davis, J., Zhu, D., Kashima, D.T., Leroueil, M., Pan, C., Montine, K.S. \& Zhang, J. (2007). "Identification of novel proteins affected by rotenone in mitochondria of dopaminergic cells." BMC Neurosci 8: 67.

Jones, N. (2010). "PINK1 targets dysfunctional mitochondria for autophagyin Parkinson disease." Nat Rev Neurol 6(4): 181.

Jullig, M., Hickey, A.J., Middleditch, M.J., Crossman, D.J., Lee, S.C. \& Cooper, G.J. (2007). "Characterization of proteomic changes in cardiac mitochondria in streptozotocindiabetic rats using iTRAQ isobaric tags." Proteomics Clin Appl 1(6): 565-576.

Kamp, D.W., Shacter, E. \& Weitzman, S.A. (2011). "Chronic inflammation and cancer: the role of the mitochondria." Oncology (Williston Park) 25(5): 400-410, 413.

Kavazis, A.N., Alvarez, S., Talbert, E., Lee, Y. \& Powers, S.K. (2009). "Exercise training induces a cardioprotective phenotype and alterations in cardiac subsarcolemmal and intermyofibrillar mitochondrial proteins." Am J Physiol Heart Circ Physiol 297(1): H144-152.

Kim, N., Lee, Y., Kim, H., Joo, H., Youm, J.B., Park, W.S., Warda, M., Cuong, D.V. \& Han, J. (2006). "Potential biomarkers for ischemic heart damage identified in mitochondrial proteins by comparative proteomics." Proteomics 6(4): 1237-1249.

Klose, J. (1975). "Protein mapping by combined isoelectric focusing and electrophoresis of mouse tissues. A novel approach to testing for induced point mutations in mammals." Humangenetik 26(3): 231-243.

Koopman, W.J., Nijtmans, L.G., Dieteren, C.E., Roestenberg, P., Valsecchi, F., Smeitink, J.A. \& Willems, P.H. (2010). "Mammalian mitochondrial complex I: biogenesis, regulation, and reactive oxygen species generation." Antioxid Redox Signal 12(12): 1431-1470.

Kowald, A. \& Kirkwood, T.B. (2011). "Evolution of the mitochondrial fusion-fission cycle and its role in aging." Proc Natl Acad Sci U S A 108(25): 10237-10242.

Krebs, H.A. (1940). The citric acid cycle. , Department of Biochemistry, The University of Sheffield.

Lanza, I.R., Short, D.K., Short, K.R., Raghavakaimal, S., Basu, R., Joyner, M.J., McConnell, J.P. \& Nair, K.S. (2008). "Endurance exercise as a countermeasure for aging." Diabetes 57(11): 2933-2942.

Lasonder, E., Janse, C.J., van Gemert, G.J., Mair, G.R., Vermunt, A.M., Douradinha, B.G., van Noort, V., Huynen, M.A., Luty, A.J., Kroeze, H., Khan, S.M., Sauerwein, R.W., Waters, A.P., Mann, M. \& Stunnenberg, H.G. (2008). "Proteomic profiling of 
Plasmodium sporozoite maturation identifies new proteins essential for parasite development and infectivity." PLoS Pathog 4(10): e1000195.

Law, M.R., Wald, N.J. \& Rudnicka, A.R. (2003). "Quantifying effect of statins on low density lipoprotein cholesterol, ischaemic heart disease, and stroke: systematic review and meta-analysis." BMJ 326(7404): 1423.

Lee, Y.H., Boelsterli, U.A., Lin, Q. \& Chung, M.C. (2008). "Proteomics profiling of hepatic mitochondria in heterozygous Sod $2+/-$ mice, an animal model of discreet mitochondrial oxidative stress." Proteomics 8(3): 555-568.

Lefort, N., Yi, Z., Bowen, B., Glancy, B., De Filippis, E.A., Mapes, R., Hwang, H., Flynn, C.R., Willis, W.T., Civitarese, A., Hojlund, K. \& Mandarino, L.J. (2009). "Proteome profile of functional mitochondria from human skeletal muscle using one-dimensional gel electrophoresis and HPLC-ESI-MS/MS." J Proteomics 72(6): 1046-1060.

Liesa, M., Palacin, M. \& Zorzano, A. (2009). "Mitochondrial dynamics in mammalian health and disease." Physiol Rev 89(3): 799-845.

Lilley, K.S. \& Friedman, D.B. (2004). "All about DIGE: quantification technology for differential-display 2D-gel proteomics." Expert Rev Proteomics 1(4): 401-409.

Link, A.J., Eng, J., Schieltz, D.M., Carmack, E., Mize, G.J., Morris, D.R., Garvik, B.M. \& Yates, J.R., 3rd (1999). "Direct analysis of protein complexes using mass spectrometry." Nat Biotechnol 17(7): 676-682.

Liu, X., Kim, C.N., Yang, J., Jemmerson, R. \& Wang, X. (1996). "Induction of apoptotic program in cell-free extracts: requirement for dATP and cytochrome c." Cell 86(1): 147-157.

Lopez, M.F. \& Melov, S. (2002). "Applied proteomics: mitochondrial proteins and effect on function." Circ Res 90(4): 380-389.

Lovell, M.A., Xiong, S., Markesbery, W.R. \& Lynn, B.C. (2005). "Quantitative proteomic analysis of mitochondria from primary neuron cultures treated with amyloid beta peptide." Neurochem Res 30(1): 113-122.

Lu, D., Goussev, A., Chen, J., Pannu, P., Li, Y., Mahmood, A. \& Chopp, M. (2004). "Atorvastatin reduces neurological deficit and increases synaptogenesis, angiogenesis, and neuronal survival in rats subjected to traumatic brain injury." $J$ Neurotrauma 21(1): 21-32.

Margulis, L. (1970). Origin of Eukaryotic Cells. . New Haven, Yale University Press.

Martorell, L., Segues, T., Folch, G., Valero, J., Joven, J., Labad, A. \& Vilella, E. (2006). "New variants in the mitochondrial genomes of schizophrenic patients." Eur J Hum Genet 14(5): 520-528.

Mathy, G. \& Sluse, F.E. (2008). "Mitochondrial comparative proteomics: strengths and pitfalls." Biochim Biophys Acta 1777(7-8): 1072-1077.

McMillin, J.B. \& Dowhan, W. (2002). "Cardiolipin and apoptosis." Biochim Biophys Acta 1585(2-3): 97-107.

Meany, D.L., Xie, H., Thompson, L.V., Arriaga, E.A. \& Griffin, T.J. (2007). "Identification of carbonylated proteins from enriched rat skeletal muscle mitochondria using affinity chromatography-stable isotope labeling and tandem mass spectrometry." Proteomics 7(7): 1150-1163.

Meisinger, C., Sickmann, A. \& Pfanner, N. (2008). "The mitochondrial proteome: from inventory to function." Cell 134(1): 22-24.

Misko, A., Jiang, S., Wegorzewska, I., Milbrandt, J. \& Baloh, R.H. (2010). "Mitofusin 2 is necessary for transport of axonal mitochondria and interacts with the Miro/Milton complex." J Neurosci 30(12): 4232-4240. 
Modica-Napolitano, J.S., Lagace, C.J., Brennan, W.A. \& Aprille, J.R. (2003). "Differential effects of typical and atypical neuroleptics on mitochondrial function in vitro." Arch Pharm Res 26(11): 951-959.

Motoyama, A. \& Yates, J.R., 3rd (2008). "Multidimensional LC separations in shotgun proteomics." Anal Chem 80(19): 7187-7193.

Multani, P., White, C.A. \& Grillo-Lopez, A. (2001). "Non-Hodgkin's lymphoma: review of conventional treatments." Curr Pharm Biotechnol 2(4): 279-291.

Murphy, M.P. \& Smith, R.A. (2000). "Drug delivery to mitochondria: the key to mitochondrial medicine." Adv Drug Deliv Rev 41(2): 235-250.

O'Connell, K. \& Ohlendieck, K. (2009). "Proteomic DIGE analysis of the mitochondriaenriched fraction from aged rat skeletal muscle." Proteomics 9(24): 5509-5524.

O'Farrell, P.H. (1975). "High resolution two-dimensional electrophoresis of proteins." J Biol Chem 250(10): 4007-4021.

Ong, S.B. \& Hausenloy, D.J. (2010). "Mitochondrial morphology and cardiovascular disease." Cardiovasc Res 88(1): 16-29.

Ong, S.E., Blagoev, B., Kratchmarova, I., Kristensen, D.B., Steen, H., Pandey, A. \& Mann, M. (2002). "Stable isotope labeling by amino acids in cell culture, SILAC, as a simple and accurate approach to expression proteomics." Mol Cell Proteomics 1(5): 376-386.

Osborne, N.N., Schwarz, M. \& Pergande, G. (1996). "Protection of rabbit retina from ischemic injury by flupirtine." Invest Ophthalmol Vis Sci 37(2): 274-280.

Otera, H. \& Mihara, K. (2011). "Molecular mechanisms and physiologic functions of mitochondrial dynamics." J Biochem 149(3): 241-251.

Pagliarini, D.J., Calvo, S.E., Chang, B., Sheth, S.A., Vafai, S.B., Ong, S.E., Walford, G.A., Sugiana, C., Boneh, A., Chen, W.K., Hill, D.E., Vidal, M., Evans, J.G., Thorburn, D.R., Carr, S.A. \& Mootha, V.K. (2008). "A mitochondrial protein compendium elucidates complex I disease biology." Cell 134(1): 112-123.

Pan, Y. \& Shadel, G.S. (2009). "Extension of chronological life span by reduced TOR signaling requires down-regulation of Sch9p and involves increased mitochondrial OXPHOS complex density." Aging (Albany NY) 1(1): 131-145.

Perovic, S., Bohm, M., Meesters, E., Meinhardt, A., Pergande, G. \& Muller, W.E. (1998). "Pharmacological intervention in age-associated brain disorders by Flupirtine: Alzheimer's and prion diseases." Mech Ageing Dev 101(1-2): 1-19.

Petriz, B.A., Gomes, C.P., Rocha, L.A., Rezende, T.M. \& Franco, O.L. (2011). "Proteomics applied to exercise physiology: a cutting-edge technology." J Cell Physiol.

Phillips, D., Aponte, A.M., Covian, R. \& Balaban, R.S. (2011). "Intrinsic protein kinase activity in mitochondrial oxidative phosphorylation complexes." Biochemistry 50(13): 2515-2529.

Pienaar, I.S., Schallert, T., Hattingh, S. \& Daniels, W.M. (2009). "Behavioral and quantitative mitochondrial proteome analyses of the effects of simvastatin: implications for models of neural degeneration." J Neural Transm 116(7): 791-806.

Rabilloud, T., Kieffer, S., Procaccio, V., Louwagie, M., Courchesne, P.L., Patterson, S.D., Martinez, P., Garin, J. \& Lunardi, J. (1998). "Two-dimensional electrophoresis of human placental mitochondria and protein identification by mass spectrometry: toward a human mitochondrial proteome." Electrophoresis 19(6): 1006-1014.

Rajanikant, G.K., Zemke, D., Kassab, M. \& Majid, A. (2007). "The therapeutic potential of statins in neurological disorders." Curr Med Chem 14(1): 103-112.

Reinders, J. \& Sickmann, A. (2007). "Proteomics of yeast mitochondria." Methods Mol Biol 372: 543-557. 
Ross, P.L., Huang, Y.N., Marchese, J.N., Williamson, B., Parker, K., Hattan, S., Khainovski, N., Pillai, S., Dey, S., Daniels, S., Purkayastha, S., Juhasz, P., Martin, S., BartletJones, M., He, F., Jacobson, A. \& Pappin, D.J. (2004). "Multiplexed protein quantitation in Saccharomyces cerevisiae using amine-reactive isobaric tagging reagents." Mol Cell Proteomics 3(12): 1154-1169.

Ruepp, S.U., Tonge, R.P., Shaw, J., Wallis, N. \& Pognan, F. (2002). "Genomics and proteomics analysis of acetaminophen toxicity in mouse liver." Toxicol Sci 65(1): 135-150.

Sahlin, K., Shabalina, I.G., Mattsson, C.M., Bakkman, L., Fernstrom, M., Rozhdestvenskaya, Z., Enqvist, J.K., Nedergaard, J., Ekblom, B. \& Tonkonogi, M. (2010). "Ultraendurance exercise increases the production of reactive oxygen species in isolated mitochondria from human skeletal muscle." J Appl Physiol 108(4): 780-787.

Santoni, V., Molloy, M. \& Rabilloud, T. (2000). "Membrane proteins and proteomics: un amour impossible?" Electrophoresis 21(6): 1054-1070.

Saraste, M. (1999). "Oxidative phosphorylation at the fin de siècle. ." Science 283: 1488-1493.

Sarsour, E.H., Kumar, M.G., Chaudhuri, L., Kalen, A.L. \& Goswami, P.C. (2009). "Redox control of the cell cycle in health and disease." Antioxid Redox Signal 11(12): 2985-3011.

Schagger, H. \& von Jagow, G. (1991). "Blue native electrophoresis for isolation of membrane protein complexes in enzymatically active form." Anal Biochem 199(2): 223-231.

Scheffler, I.E. (2008). Mitochondria. Hoboken, New Jersey, J. Wiley and Sons, Inc., .

Schirmer, T. (1998). "General and specific porins from bacterial outer membranes." J Struct Biol 121(2): 101-109.

Schluter, T., Struy, H. \& Schonfeld, P. (2000). "Protection of mitochondrial integrity from oxidative stress by the triaminopyridine derivative flupirtine." FEBS Lett 481(1): 42-46.

Schwerzmann, K., Cruz-Orive, L.M., Eggman, R., Sanger, A. \& Weibel, E.R. (1986). "Molecular architecture of the inner membrane of mitochondria from rat liver: a combined biochemical and stereological study." J Cell Biol 102(1): 97-103.

Short, K.R.B., Maureen L.; Kahl, Jane; Singh, Ravinder; Coenen-Schimke, Jill; Raghavakaimal, Sreekumar and Nair, K. Sreekumaran (2005). "Decline in skeletal muscle mitochondrial function with aging in humans." PNAS 102 (15): 7.

Siddik, Z.H. (2003). "Cisplatin: mode of cytotoxic action and molecular basis of resistance." Oncogene 22(47): 7265-7279.

Stowe, D.F. \& Camara, A.K. (2009). "Mitochondrial reactive oxygen species production in excitable cells: modulators of mitochondrial and cell function." Antioxid Redox Signal 11(6): 1373-1414.

Sun, L., Shen, W., Liu, Z., Guan, S., Liu, J. \& Ding, S. (2010). "Endurance exercise causes mitochondrial and oxidative stress in rat liver: effects of a combination of mitochondrial targeting nutrients." Life Sci 86(1-2): 39-44.

Tao, D., Zhu, G., Sun, L., Ma, J., Liang, Z., Zhang, W., Zhang, L. \& Zhang, Y. (2009). "Serially coupled microcolumn reversed phase liquid chromatography for shotgun proteomic analysis." Proteomics 9(7): 2029-2036.

Taylor, N.L., Heazlewood, J.L. \& Millar, A.H. (2011). "The Arabidopsis thaliana 2-D gel mitochondrial proteome: Refining the value of reference maps for assessing protein abundance, contaminants and post-translational modifications." Proteomics 11(9): 1720-1733.

Unlu, M., Morgan, M.E. \& Minden, J.S. (1997). "Difference gel electrophoresis: a single gel method for detecting changes in protein extracts." Electrophoresis 18(11): 2071-2077. 
van den Ecker, D., van den Brand, M.A., Bossinger, O., Mayatepek, E., Nijtmans, L.G. \& Distelmaier, F. (2010). "Blue native electrophoresis to study mitochondrial complex I in C. elegans." Anal Biochem 407(2): 287-289.

Vega, G.L., Weiner, M.F., Lipton, A.M., Von Bergmann, K., Lutjohann, D., Moore, C. \& Svetlik, D. (2003). "Reduction in levels of 24S-hydroxycholesterol by statin treatment in patients with Alzheimer disease." Arch Neurol 60(4): 510-515.

Wallace, D.C. (1999). "Mitochondrial diseases in man and mouse." Science 283(5407): 1482-1488.

Wang, D. \& Lippard, S.J. (2005). "Cellular processing of platinum anticancer drugs." Nat Rev Drug Discov 4(4): 307-320.

Wang, J., Bai, L., Li, J., Sun, C., Zhao, J., Cui, C., Han, K., Liu, Y., Zhuo, X., Wang, T., Liu, P., Fan, F., Guan, Y. \& Ma, A. (2009). "Proteomic analysis of mitochondria reveals a metabolic switch from fatty acid oxidation to glycolysis in the failing heart." Sci China C Life Sci 52(11): 1003-1010.

Weissig, V., Cheng, S.M. \& D'Souza, G.G. (2004). "Mitochondrial pharmaceutics." Mitochondrion 3(4): 229-244.

Westermann, B. (2010). "Mitochondrial fusion and fission in cell life and death." Nat Rev Mol Cell Biol 11(12): 872-884.

WHO (2011). The world malaria reort 2008. Geneva.

Wilkins, M.R., Pasquali, C., Appel, R.D., Ou, K., Golaz, O., Sanchez, J.C., Yan, J.X., Gooley, A.A., Hughes, G., Humphery-Smith, I., Williams, K.L. \& Hochstrasser, D.F. (1996). "From proteins to proteomes: large scale protein identification by two-dimensional electrophoresis and amino acid analysis." Biotechnology (N Y) 14(1): 61-65.

Yaffe, M.P. (1999). "The machinery of mitochondrial inheritance and behavior." Science 283(5407): 1493-1497.

Yoon, Y.G., Koob, M.D. \& Yoo, Y.H. (2010). "Re-engineering the mitochondrial genomes in mammalian cells." Anat Cell Biol 43(2): 97-109.

Zhang, A., Williamson, C.D., Wong, D.S., Bullough, M.D., Brown, K.J., Hathout, Y. \& Colberg-Poley, A.M. (2011). "Quantitative proteomic analyses of human cytomegalovirus-induced restructuring of endoplasmic reticulum-mitochondrial contacts at late times of infection." Mol Cell Proteomics.

Zhang, F., Suarez, G., Sha, J., Sierra, J.C., Peterson, J.W. \& Chopra, A.K. (2009). "Phospholipase A2-activating protein (PLAA) enhances cisplatin-induced apoptosis in HeLa cells." Cell Signal 21(7): 1085-1099.

Zhang, J., Li, X., Mueller, M., Wang, Y., Zong, C., Deng, N., Vondriska, T.M., Liem, D.A., Yang, J.I., Korge, P., Honda, H., Weiss, J.N., Apweiler, R. \& Ping, P. (2008). "Systematic characterization of the murine mitochondrial proteome using functionally validated cardiac mitochondria." Proteomics 8(8): 1564-1575.

Zhang, J., Liem, D.A., Mueller, M., Wang, Y., Zong, C., Deng, N., Vondriska, T.M., Korge, P., Drews, O., Maclellan, W.R., Honda, H., Weiss, J.N., Apweiler, R. \& Ping, P. (2008). "Altered proteome biology of cardiac mitochondria under stress conditions." J Proteome Res 7(6): 2204-2214.

Zhang. X, S.X.O., Gao. Y.T, Yang. G, Li. Q, Li. H, et al., (2003). "Soy food consumption is associated with lower risk of coronary heart disease in Chinese women. ." J.Nutr. 133: 2874-2878.

Zorzano, A. (2009). "Regulation of mitofusin-2 expression in skeletal muscle." Appl Physiol Nutr Metab 34(3): 433-439. 


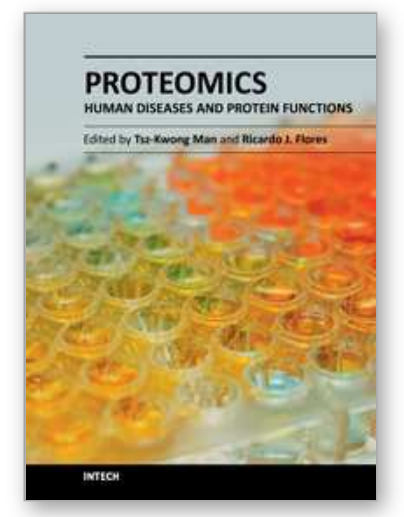

\author{
Proteomics - Human Diseases and Protein Functions \\ Edited by Prof. Tsz Kwong Man
}

ISBN 978-953-307-832-8

Hard cover, 438 pages

Publisher InTech

Published online 10, February, 2012

Published in print edition February, 2012

Biomedical research has entered a new era of characterizing a disease or a protein on a global scale. In the post-genomic era, Proteomics now plays an increasingly important role in dissecting molecular functions of proteins and discovering biomarkers in human diseases. Mass spectrometry, two-dimensional gel electrophoresis, and high-density antibody and protein arrays are some of the most commonly used methods in the Proteomics field. This book covers four important and diverse areas of current proteomic research: Proteomic Discovery of Disease Biomarkers, Proteomic Analysis of Protein Functions, Proteomic Approaches to Dissecting Disease Processes, and Organelles and Secretome Proteomics. We believe that clinicians, students and laboratory researchers who are interested in Proteomics and its applications in the biomedical field will find this book useful and enlightening. The use of proteomic methods in studying proteins in various human diseases has become an essential part of biomedical research.

\title{
How to reference
}

In order to correctly reference this scholarly work, feel free to copy and paste the following:

Bernardo A. Petriz, Jeeser A. Almeida, Mirna S. Freire, Luiz A. O. Rocha, Taia M. B. Rezende and Octavio L. Franco (2012). Mitochondrial Proteomics: From Structure to Function, Proteomics - Human Diseases and Protein Functions, Prof. Tsz Kwong Man (Ed.), ISBN: 978-953-307-832-8, InTech, Available from: http://www.intechopen.com/books/proteomics-human-diseases-and-protein-functions/mitochondrialproteomics-from-structure-to-function

\section{INTECH}

open science | open minds

\section{InTech Europe}

University Campus STeP Ri

Slavka Krautzeka 83/A

51000 Rijeka, Croatia

Phone: +385 (51) 770447

Fax: +385 (51) 686166

www.intechopen.com

\section{InTech China}

Unit 405, Office Block, Hotel Equatorial Shanghai

No.65, Yan An Road (West), Shanghai, 200040, China

中国上海市延安西路65号上海国际贵都大饭店办公楼 405 单元

Phone: +86-21-62489820

Fax: $+86-21-62489821$ 
(C) 2012 The Author(s). Licensee IntechOpen. This is an open access article distributed under the terms of the Creative Commons Attribution 3.0 License, which permits unrestricted use, distribution, and reproduction in any medium, provided the original work is properly cited. 